\title{
3D models related to the publication: First partial cranium of Togocetus from Kpogamé (Togo) and the protocetid diversity in the Togolese phosphate basin.
}

\author{
Koffi Evenyon Kassegne ${ }^{1}$, Mickaël Mourlam² ${ }^{2}$ Guillaume Guinot ${ }^{2}$, Yawovi Zikpi Amoudji ${ }^{1}$, Jérémy E. Martin ${ }^{3}$, Kodjo \\ Adika Togbe ${ }^{1}$, Ampah Kodjo Johnson ${ }^{1 *}$, Lionel Hautier ${ }^{2 *}$ \\ ${ }^{1}$ Département de Géologie, Faculté des Sciences, Université de Lomé, B.P. 1515 Lomé, Togo ; christophe_johnson yahoo.fr and kevenyon gmail.com \\ ${ }^{2}$ Institut des Sciences de l'Evolution de Montpellier, Université Montpellier, CNRS, IRD, Cc 064; place Eugène Bataillon, 34095 Montpellier Cedex 5, \\ France; email: lionel.hautier@umontpellier.fr \\ ${ }^{3}$ Univ. Lyon, ENS de Lyon, Université Claude Bernard Lyon 1, CNRS, UMR 5276 Laboratoire de Géologie de Lyon : Terre, Planètes, Environnement, \\ F-69342 46 Allée d'Italie, Lyon, France, jeremy.martin@ens-lyon.fr \\ *Corresponding authors: Dr. Lionel Hautier lionel.hautier@umontpellier.fr, and Dr. Christophe Johnson christophe_johnson@yahoo.fr
}

\section{Abstract}

This contribution contains the 3D models described and figured in the following publication: Kassegne K. E., Mourlam M. J., Guinot G., Amoudji Y. Z., Martin J. E., Togbe K. A., Johnson A. K., Hautier L. 2021. First partial cranium of Togocetus from Kpogamé (Togo) and the protocetid diversity in the Togolese phosphate basin. Annales de Paléontologie, Issue 2, April-June 2021, 102488. https://doi.org/10.1016/j.annpal.2021.102488

Keywords: Comparative anatomy, Middle Eocene, Paleoenvironment, Phylogeny, Protocetidae

Submitted:2021-04-16, published online:2021-06-22. https://doi.org/10.18563/journal.m3.143

\section{Model Id nr \\ M3\#768 \\ M3\#770}

\section{Description}

3D surface virtual restoration. $\mu \mathrm{CT}$ data of the cranium. Resolution: $315.6 \mu \mathrm{m}$

Table 1. List of 3D data representing ULDG-KPO1 (Togocetus $c f$. traversei models). Collection: University of Lomé, Togo.

\section{INTRODUCTION}

We present here the 3D model of a partial skull of cetacean discovered in middle Eocene phosphate deposits from Kpogamé (Togo). The dental and cranial characteristics of the new Togolese specimen recall those of protocetid taxa described in Africa, Asia, and North America, but also display significant differences. A 3D model of the cranium, teeth, and vomer was here reconstructed (see Fig. 1 and Table 1) in order to reveal hidden anatomical features (e.g., tooth roots). In particular, we showed that the new specimen shares a number of morphological features with the Togolese taxon Togocetus (Kassegne et al. 2021). Phylogenetic analyses recovered the new specimen close to Togocetus as the first offshoot of protocetids, which is consistent with the middle Lutetian age proposed for the Togolese phosphate deposits. These results enabled us to assign the specimen ULDG-KPO1 to Togocetus cf. traversei, so that it represents the first and most complete cranial remain of Togocetus.

\section{METHODS}

The cranium, upper tooth rows, and vomer were imaged using high-resolution microtomography $(\mu \mathrm{CT})$ at the MRI platform of the Institut des Sciences de l'Evolution de Montpellier (ISEM). Image segmentation of the cranium elements was performed on the $\mu \mathrm{CT}$ images with Avizo.Lite 2019.4 (Thermofisher Scientific) software using the segmentation threshold selection tool. The 3D virtual restoration was performed with MorphoDig software (v. 1.5.3; Lebrun, 2018). The 3D surface model of the skull is provided in .vtk format, and can therefore be opened with a wide range of freeware.

\section{ACKNOWLEDGEMENTS}

We thank the Department of Geology of the University of Lomé. We also warmly thank M. Abalo Kézié, general director of SNPT, as well as employees from these companies, M. Bikiliniwé Ekpao, M. Kudzo D'almeida, M. Adodo Goe Akue, M. Mazama-Esso Bidabi, M. Laba Minza, M. Sizing Adom, M. Kossi Karim and M. Fan-Name Kanfeli, for providing access and sampling permissions. We are grateful to Maëva J. Orliac (ISEM) for the 3D surface of the basicranium of morphotype $\gamma$ (UM-KPG-M 73) and to Kathlyn Smith (Georgia Southern University) for the picture of Georgiacetus' basicranium (GSM 350). We thank Camille Auclair (Kraniata, France, www.kraniata.com) for the exquisite preparation of the specimen ULDG-KPO1. 3D data acquisition was performed using the $\mu \mathrm{CT}$ facilities of the MRI platform member of the national infrastructure France-Bio Imaging supported by the French National Research Agency (ANR-10-INBS-04, 'Investments for the future') and of the Labex CEMEB (ANR-10-LABX-0004) and NUMEV (ANR-10-LABX-0020). This study is part of the PaleonTogo project, which is partly supported by a CNRS PICS grant (n8229424) and the National Geographic Society (grant NGS-72222R-20). 

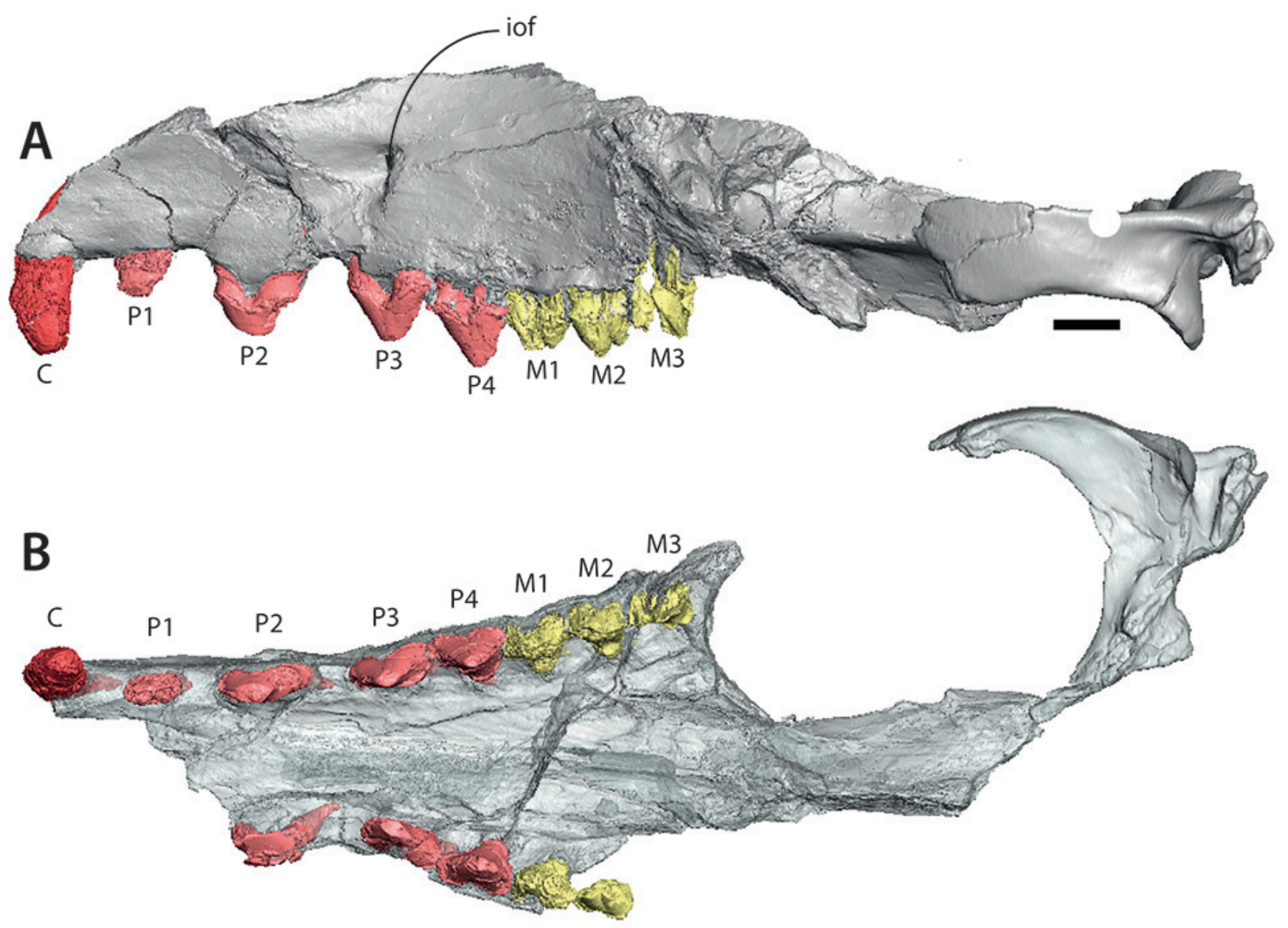

Figure 1. 3D reconstruction of the cranium and teeth of ULDG-KPO1. A, lateral view of the left side of ULDG-KPO1; B, palatine view. Abbreviations: C, canine; iof, infraorbital foramen; M, molar; P, premolar. The cranium elements are in grey, canine in dark red, premolar in light red and molar in yellow. Scale bar represents $2 \mathrm{~cm}$. 


\section{BIBLIOGRAPHY}

Kassegne K. E., Mourlam M. J., Guinot G., Amoudji Y. Z., Martin J. E., Togbe K. A., Johnson A. K., Hautier L. 2021. First partial cranium of Togocetus from Kpogamé (Togo) and the protocetid diversity in the Togolese phosphate basin. Annales de Paléontologie volume 107, Issue 2, April-June 2021, 102488. https://doi.org/10.1016/j.annpal.2021.102488 